\title{
Forthcoming in Information Services \& Use
}

\section{Volume 5, Number 5}

This issue will include:

Integrated communications and work efficiency: impacts on organizational structure and power, by R.T. Wigand

Transfer of the EPA/NIH Chemical Information System (CIS) to private management, by S.T. Kadec and A. Jover

An experiment in pricing mechanism for online information retrieval, by P.L. Holmes

\section{Volume 5, Number 6}

This issue will include:

The use of the magazine method in interactive videotex through intelligent videotex decoders, by I. Sebestyén

Database and online system usage in a for-profit general researchenvironment, by R. Basch

The integration of the information and communication functions, and the marketing of the resulting products, by S.C. Harris

A conceptual framework for the use of scientific and technical information in national development in Nigeria, by E.E. Nkereuwem

Conference Report: ASIDIC 1985 Fall Meeting 